\title{
A study of white etching crack bearing failure detection using electrostatic sensing in wind turbine gearboxes
}

\author{
K Esmaeili, M Zuercher, L Wang, T Harvey, W Holweger, N White and E Schlücker
}

Based on a paper presented at WCCM 2017, The First World Congress on Condition Monitoring, London, UK, 13-16 June 2017

White etching cracks (WECs) have been found to form in rolling element bearings as early as 6-24 months into operation, especially in large wind turbine gearboxes ${ }^{[1]}$. Despite the number of investigations conducted in both industrial and academic research over the past two to three decades, WEC formation and initiation mechanisms are still not well understood. This is due to the complexity of the factors that influence WEC formation, such as speed, load (mechanical and electrical) and lubrication, as well as a lack of effective monitoring techniques that can detect WECs prior to severe bearing failures, such as spalls on the bearing surface. Recent research has suggested that WECs can form in rolling element bearings under the influence of electrical load (potential or current) ${ }^{[2,3]}$. To investigate the feasibility of WEC detection using the electrostatic (ES) sensing technique, an ES wear site sensor was installed on a bearing test-rig where WECs had been created under the influence of electrical load. The ES responses were compared with those from an acoustic emission (AE) sensor that had been shown to detect WEC failures in a previous study ${ }^{[4]}$. The physical findings related to WEC failures in the bearings and basic analysis of the sensor signals have been reported in a parallel paper by Zuercher et al ${ }^{[3]}$. This paper focuses on the analysis of $E S$ and $A E$ signals using a time-frequency method, where correlations between the electrostatic charge signals and $A E$ measurements are found. The results suggest that electrostatic sensors have the potential to detect WEC formation in rolling element bearings.

\section{Introduction}

White etching cracks (WECs) are one of the mechanisms that cause a large number of bearing failures in wind turbine gearboxes $^{[5-7]}$. The mechanisms of WEC formation have been widely discussed over the past few decades; however, their drivers are still unclear. WECs eventually cause a failure on the surfaces of bearings but are often found to initiate in bearing subsurfaces

$K$ Esmaeili, L Wang, T Harvey, $W$ Holweger and $N$ White are with the National Centre for Advanced Tribology, University of Southampton, SouthamptonSO17 1BJ, UK.Email:kamran.esmaeili@soton.ac.uk

$M$ Zuercher and E Schlücker are with Process Machinery and System Engineering, Friedrich-Alexander University Erlangen-Nürnberg, Germany. at depths of up to $1.5 \mathrm{~mm}$. Figure 1 shows an optical image of a subsurface-initiated WEC in a bearing inner ring, taken during a test in this study. More information about the characteristics of WECs can be found in the literature ${ }^{[8-10]}$.

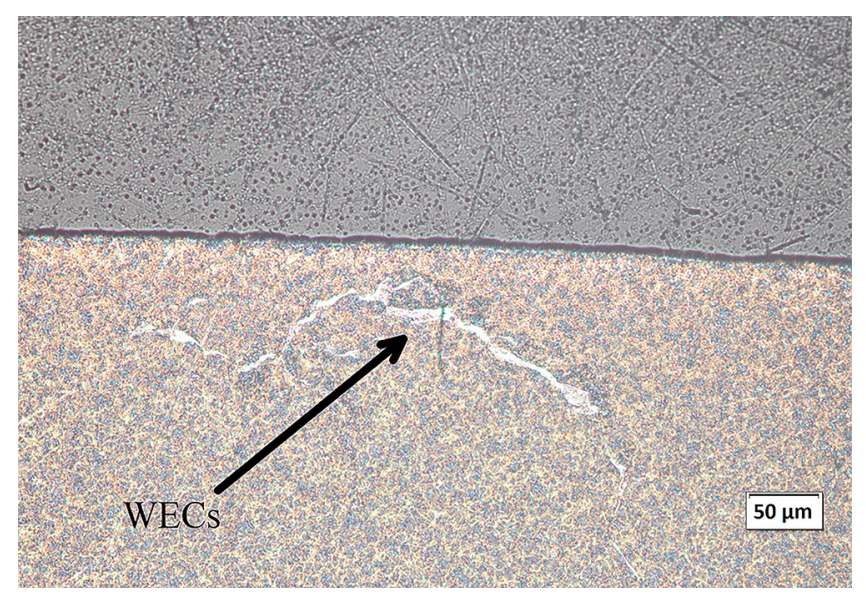

Figure 1. An optical image of a WEC observed in the inner ring of bearing 1 during test $\mathrm{A}$ (more details are given in Table 1 )

While the root causes of WECs are still unclear, one of the hypotheses suggested by Loos et $a l^{[2]}$ and Holweger et a $l^{[5]}$ involves continuous material alterations induced by current or electromagnetic fields. They suggested that:

- Self-charging of lubricants in the ball-raceway contact leads to the occurrence of a transient current flow

- The transient current flow induces a local electrical polarisation near the surface. A sudden discharge may result in the transfer of the electrical current from the bearing surface into subsurface defect domains.

Holweger et al ${ }^{[5]}$ suggested that an electric current could induce a thermal effect at material defects (for example nonmetallic inclusions, carbides, etc), which may cause an increase in thermal stress at the defect sites. The local thermal stress could then lead to a local strain and subsequently stress in the material. Localised stress could drive atoms such as carbon, chromium and silicon to migrate and diffuse, leading to instability of the steel microstructure or WEC formation.

Loos et al ${ }^{[2]}$ suggested that a stray current through a bearing could cause the decomposition of the lubricant ${ }^{[11]}$ and subsequent 
electrochemical reactions at the bearing surfaces forming solvated hydrogen cations that may diffuse into the bulk of the material. This has been suggested to lead to WEC formation ${ }^{[2]}$.

It has been suggested that the driving mechanism for WEC formation under the influence of electrical load is the electrical discharges resulting from exceedance of the lubricant field strength. As shown in Figure 2, the electrical circuit of the racelubricant ball contact in a bearing can be simplified as a resistor in parallel with a capacitor. When the supplied potential difference is low, the behaviour of the contact is ohmic. As the supply voltage increases, the electrical field at the contact reaches a level that can break lubricant field strength and cause electrical discharge.

According to the studies conducted by Loos et al ${ }^{[2]}$ and Zuercher et al ${ }^{[3]}$, WECs formed in rolling element bearings at an electrical current density below even $200 \mu \mathrm{A} / \mathrm{mm}^{2}$ across the contact. However, the mechanisms of WEC formation under electrical load are not clear.

In addition, although sensing techniques such as vibration monitoring have been shown to be effective when detecting surface damage in bearings ${ }^{[12,13]}$, they cannot detect subsurface cracks. However, acoustic emission sensors have shown promising results when detecting subsurface crack formation in rolling element bearings ${ }^{[14,15]}$.

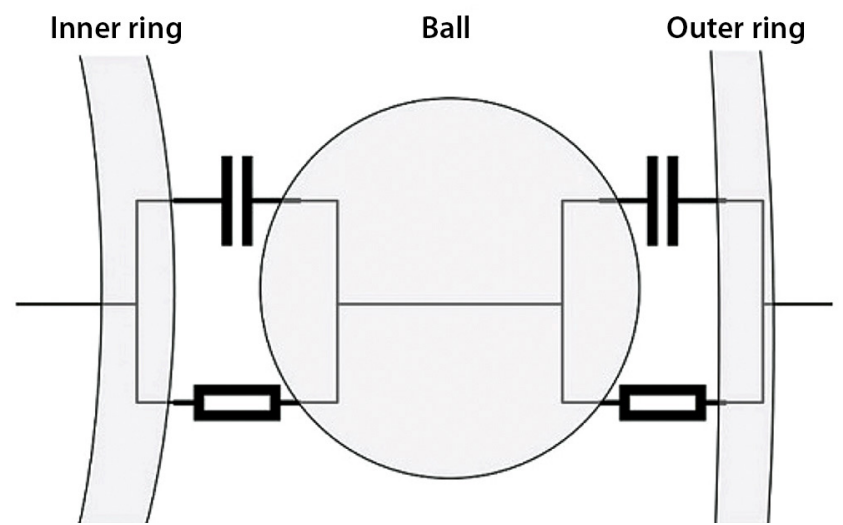

Figure 2. Simplified electrical circuit for a rolling element bearing incorporating a capacitor and a resistor in parallel ${ }^{[16]}$

A recent study by Barteldes and Holweger ${ }^{[4]}$ investigated the feasibility of the acoustic emission (AE) sensing technique when detecting WEC formation in bearings. It was found that a sudden and continuous increase in $\mathrm{AE}$ energy was observed prior to the final bearing failure due to WEC formation. The rise in AE signals was related to the burst of damage, the formation of white etching areas (WEAs) causing surface bulging and the initiation and propagation of the crack. However, no detailed experiment was conducted to confirm the time at which WECs were initiated in the bearings.

The electrostatic (ES) sensing technique has shown promising results when identifying charges associated with surface and lubricant degradation mechanisms, such as contact potential difference $(\mathrm{CPD})^{[17-20]}$, triboemission ${ }^{[21-23]}$ and debris formation $^{[24,25]}$, as well as identifying charges associated with the double layer effect ${ }^{[26]}$ (lubricant-surface interaction). ES sensors have also shown to be able to detect bearing failures in advance of vibration monitoring techniques ${ }^{[27-29]}$. Hence, the ES sensing technique might have the potential to detect WEC failures under electrical load influences when a charging and discharging phenomenon occurs in rolling element bearings.

In order to assess the feasibility of detecting WECs using the ES sensing technique, a test-rig, located at the University of Erlangen, was modified to incorporate the ES sensor together with an $\mathrm{AE}$ sensor. Other operating parameters, such as temperature, lubricant flow rate and axial load, were also monitored in order to develop an understanding of the WEC formation mechanism and evaluate the feasibility of the ES sensor in detecting WECs under the influence of electrical load. This paper presents the results from the $\mathrm{ES}$ and $\mathrm{AE}$ sensors, focusing on assessing the charge signatures in the ES signals for monitoring WEC failure events in rolling element bearings.

\section{Experimental details}

This section presents the experimental information that is essential to the discussions in this paper. Full details of the testrig, sensors, test bearing, test programme and post-test bearing failure analysis can be found in a parallel paper ${ }^{[3]}$.

\subsection{Experimental test-rig}

Figure 3 includes a schematic of the bearing test-rig. The testrig incorporates two type 6203 deep-groove ball bearings with martensitic hardened SAE 52100 grade steel. The bearings are axially loaded and located inside the bearing casing. As can be seen in Figure 3(d), the threaded holes in the bearing casing allow for the installation of the temperature sensors to monitor the temperature of the bearings. Similar threaded holes exist on the other side of the bearing casing and are used to apply an electrical potential to the test bearings (the electrical circuit is shown in Figure 3(b)).

A range of potential difference can be applied to the electrical circuit of the bearings, resulting in a potential difference across the bearing contacts. The characterisation test in Figure 4 shows that the supplied voltage increased linearly from $0 \mathrm{~V}$ to $15 \mathrm{~V}$ over a period of $200 \mathrm{~s}$, while the potential measured across the bearings initially increased linearly from $0 \mathrm{~V}$ to approximately $4 \mathrm{~V}$ at $160 \mathrm{~s}$, then started to fluctuate around this voltage. With a further increase in the supplied potential, the voltage across the contact started to decrease while the fluctuations in the signals increased further. Snapshots of high-frequency voltage responses captured by an oscilloscope showed highly active discharging events starting from about $160 \mathrm{~s}$. As the supplied voltage increased, the frequency of the discharges increased substantially, while the amplitude of the discharges reduced. This was thought to be due to a decrease in the electrical resistance at the bearing contact (see oscilloscope windows in Figure 4).

Tests were automatically terminated as soon as the temperature of one of the bearings exceeded the $120^{\circ} \mathrm{C}$ threshold. An ES sensor and an $\mathrm{AE}$ sensor were installed close to the test bearings on the top and bottom of the bearing casing, respectively. These sensors were located between bearings 1 and 2, as shown in Figure 3(d).

During testing, the oil volume flow rate, the axial load on the bearings, the temperature of the test bearings, the electrical potential supplied, the potential difference across the bearings and the regulating resistor were measured. 


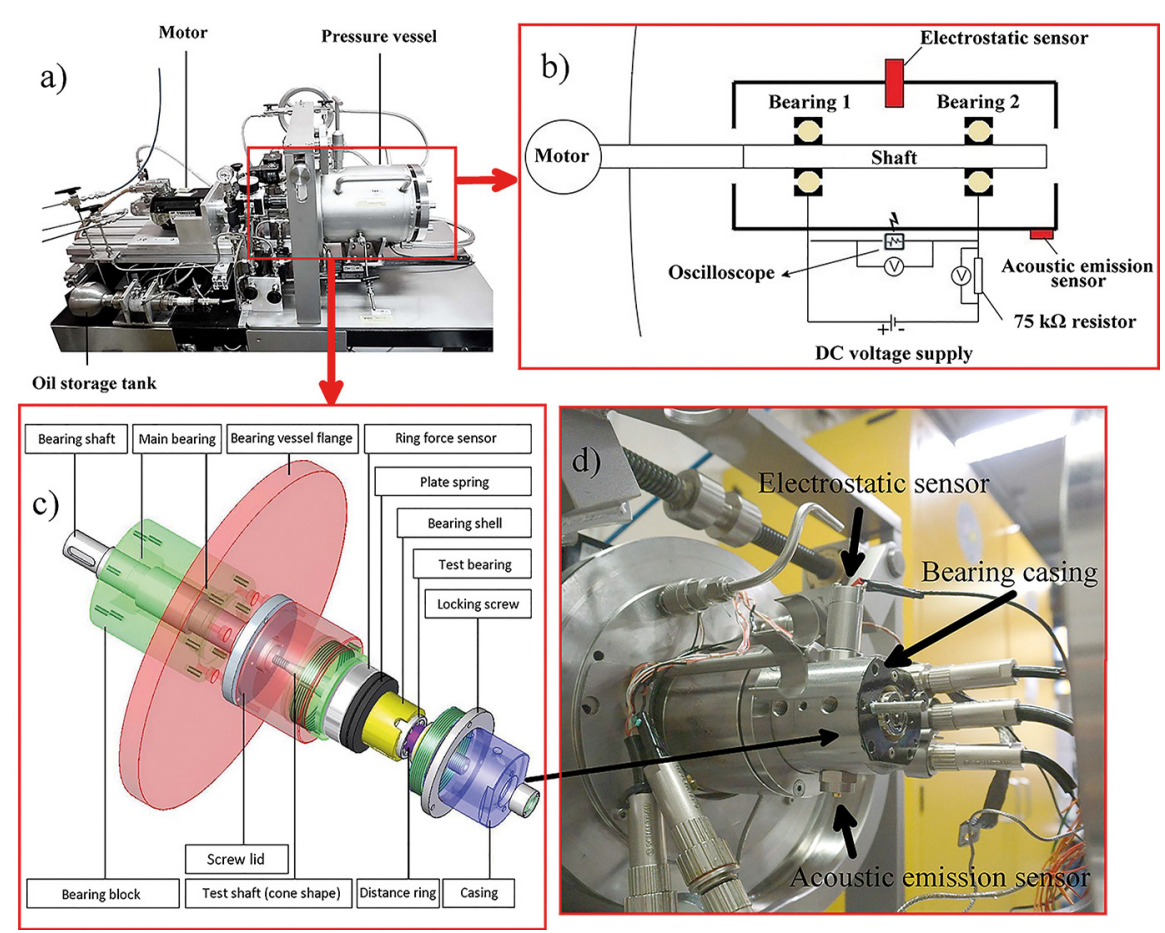

Figure 3. (a) The test-rig including the bearing chamber; (b) a schematic of the electrical circuit showing the regulating resistor of $75 \mathrm{k} \Omega$ and bearings 1 and 2; (c) a 3D model of the shaft and the bearing casing, at which bearings 1 and 2 are located; and (d) the bearing casing and the location of the electrostatic and acoustic emission sensors on the top and bottom, respectively. The threaded holes on the bearing casing are relative to the position of the bearings inside the casing the tests in which WECs were avoided due to an increase in the lubricant flow rate.

While an initial axial load of $1800 \mathrm{~N}$ was applied to all of the tests, the axial loads measured for the bearings were seen to have varied due to the thermal expansion of the bearings caused by the frictional heat. Similarly, the frictional heat caused an increase in the temperature of the bearings, subsequently increasing the temperature of the lubricant. The temperature of the lubricant in the tank was initially at an ambient temperature of $25^{\circ} \mathrm{C}$. However, during the tests, higher levels of lubrication and bearing temperature were observed due to the frictional heat. For the tests, the shaft rotational speed was kept constant, while the electrical potential supplied and the lubricant flow rate were adjusted.

Test A failed at $19.3 \mathrm{~h}$, with WECs forming in bearing 1 under a low lubricant flow rate of $3.4 \mathrm{ml} / \mathrm{min}$ and an applied electrical potential of $15 \mathrm{~V}$. Test B was conducted by increasing the supplied potential difference by $1 \mathrm{~V}$ every $24 \mathrm{~h}$ from $6 \mathrm{~V}$. In this test, WECs were formed in bearing 1 with a running time of $142.6 \mathrm{~h}$. Test $\mathrm{C}$ was performed according to test $\mathrm{A}$ until $15.15 \mathrm{~h}$, at which point the lubricant

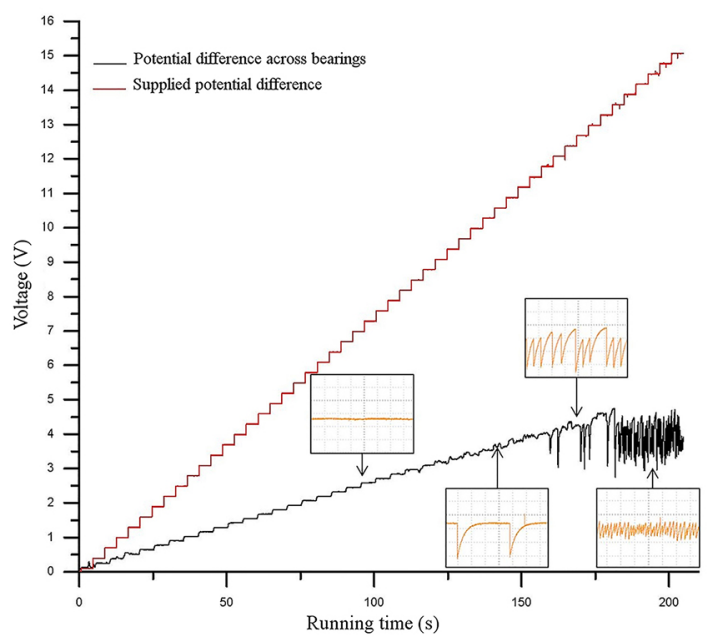

Figure 4. Electrical characterisation test for the test-rig showing discharge regions for a supplied potential of above $10 \mathrm{~V}$

\subsection{The tests}

A total of 20 tests were performed on the test-rig, after which it was concluded that a combination of a low lubricant flow rate, a moderate axial load and a significant electrical discharging may lead to the formation of WECs ${ }^{[3]}$. Three of the 20 tests, which collected electrostatic sensor data, are presented here. Details of tests $\mathrm{A}, \mathrm{B}$ and $\mathrm{C}$ are shown in Table 1. Test A represents the accelerated WEC tests, in which WECs were created in less than $22 \mathrm{~h}$. Test $\mathrm{B}$ represents those tests where the influence of low electrical potential on WEC formation were investigated. Test $\mathrm{C}$ shows one of

flow rate was increased from 3.4 to $40 \mathrm{ml} / \mathrm{min}$ and gradually reduced to $7.2 \mathrm{ml} / \mathrm{min}$ towards the end of the test at $39.4 \mathrm{~h}$. No WECs were observed in the bearings from test $\mathrm{C}$.

Table 1. Parametric conditions for tests A, B and C

\begin{tabular}{|c|c|c|c|}
\hline & Test A & Test B & Test C \\
\hline Input axial load (N) & 1800 & 1800 & 1800 \\
\hline Pressure & Ambient & Ambient & Ambient \\
\hline $\begin{array}{l}\text { Bearing shaft } \\
\text { rotational speed } \\
(\mathrm{r} / \mathrm{min})\end{array}$ & 4500 & 4500 & 4500 \\
\hline $\begin{array}{l}\text { Initial lubricant } \\
\text { temperature }\left({ }^{\circ} \mathrm{C}\right)\end{array}$ & 25 & 25 & 25 \\
\hline $\begin{array}{l}\text { Electrical potential } \\
\text { supplied (V) }\end{array}$ & $0-15$ & $\begin{array}{l}0-15 \text { (step } \\
\text { approach) }\end{array}$ & $0-15$ \\
\hline $\begin{array}{l}\text { Lubricant flow rate } \\
(\mathrm{m} \ell / \mathrm{min})\end{array}$ & 3.4 & $\begin{array}{c}\text { 0-0.5 h: } \\
5.5-3.4 \\
\text { 16-22 h: } 1 \\
22 \text { h-end: } 3.4\end{array}$ & $\begin{array}{c}0-15.15 \mathrm{~h}: \\
3.4 \\
\\
15.15 \text {-end: } \\
40 \text { h- } 7.2\end{array}$ \\
\hline Total running time $(\mathrm{h})$ & 19.3 & 142.6 & 39.4 \\
\hline WEC formation & $\begin{array}{c}\text { Yes, in } \\
\text { bearing } 1 \\
\text { inner ring }\end{array}$ & $\begin{array}{c}\text { Yes, in } \\
\text { bearing } 1 \\
\text { inner ring }\end{array}$ & $\begin{array}{c}\text { None } \\
\text { observed }\end{array}$ \\
\hline
\end{tabular}




\section{Signal analysis approach}

Signals from both ES and $\mathrm{AE}$ sensors were acquired at $1.5625 \mathrm{MHz}$ (default set-up defined by the QASS data acquisition device based on a previous study $\left.{ }^{[4]}\right)$. The signals were captured for a period of $10 \mathrm{~s}$ with an interval of $7 \mathrm{~min}$ for all of the tests. The raw signals were processed using the short-time Fourier transformation (STFT) method to investigate changes of interesting frequency components in these signals over the test duration. A similar method had previously been used to detect WEC failure events in AE signals ${ }^{[4]}$. The STFT of the ES and AE signals were calculated using ${ }^{[30]}$ :

$$
\mathrm{X}_{m}(\omega)=\sum_{n=-\infty}^{\infty} x(n) w(n-m R) e^{-j \omega n}
$$

where $x(n)$ is the signal at time $n, \omega(n)$ is the length $M$ window function (for example Hamming), $R$ is the hop size in samples between the successive STFT, $m$ is discrete and $\omega$ is continuous. The window is moved by a quarter of the sample frame at each stage. The output values are arbitrary due to a combination of the signal processing approach and the use of the preamplification factor, so the output of the STFT does not represent any physical meaning.

The absolute output of the STFT method was calculated and fed into a logarithmic function to magnify the small amplitudes and increase the reliability of the analysis.

\section{Results}

Preliminary analysis of the $\mathrm{AE}$ and $\mathrm{ES}$ signals collected from tests $\mathrm{A}, \mathrm{B}$ and $\mathrm{C}$, using the STFT method, has shown that their energy is dominated by frequencies below $50 \mathrm{kHz}$ for all of the tests. Hence, despite the sampling rate of $1.5625 \mathrm{MHz}$ used in the tests, only frequencies below $50 \mathrm{kHz}$ have been examined for both sensors. The STFT results for the ES and AE sensors, together with the lubricant flow rate, bearing temperature, axial load and voltage responses for tests $\mathrm{A}, \mathrm{B}$ and $\mathrm{C}$ are shown in Figures 5, 6 and 7, respectively. As discussed previously, tests $\mathrm{A}$ and $\mathrm{B}$ failed due to WECs, while no WECs were observed in the bearings from test $\mathrm{C}$.

As can be seen from the plots for tests A, B and C, the applied potential causes a sharp increase in the ES amplitude. Observing the results from test $\mathrm{B}$, it can be concluded that the rise in the ES amplitude has been considerable at the supplied voltage of above $10 \mathrm{~V}$. This can indicate that, due to the ohmic behaviour of the contact below $10 \mathrm{~V}$ of supplied voltage (little to no discharge), the charge transfer across the contact is minimal and thus the ES sensor does not detect a high amplitude for the electrical potential below $10 \mathrm{~V}$.
Comparing all three tests, four distinct regions were identified:

- Region 1: Running-in period, where the bearings were running under a defined load, speed, lubricant temperature and flow rate but no electrical potential was applied. During this period, the axial load measured on the bearings were shown to increase with the lubricant temperature due to cumulative frictional heat generated from the contacts. However, no significant changes were observed in the ES and AE signals;

- Region 2: Charging/discharging region. Once an electrical potential (above $10 \mathrm{~V}$ and causing electrical discharge) was applied to the bearings, a sudden increase in the ES responses was observed in all three tests while no significant changes were seen in the $\mathrm{AE}$ signals. This is thought to be caused by electrical charging/discharging effects in the bearings due to the application of an electrical potential. However, after an initial period of high electrical discharges and high ES amplitude the electrical discharges started to diminish, possibly due to the increase in the electrical resistance of the contact. It is not yet clear what mechanisms are involved in boosting the electrical resistance of the contact;

- Region 3: Steady state, where the potential difference across the bearings became stable, possibly due to the increased electrical resistance of the contact. Few activities were observed in the $\mathrm{ES}$ and $\mathrm{AE}$ signals; and

- Region 4: Running-to-failure region. As the test reached the end of region 3 , small activities were observed in the $\mathrm{AE}$ signals. This was suddenly followed by a burst in the amplitude

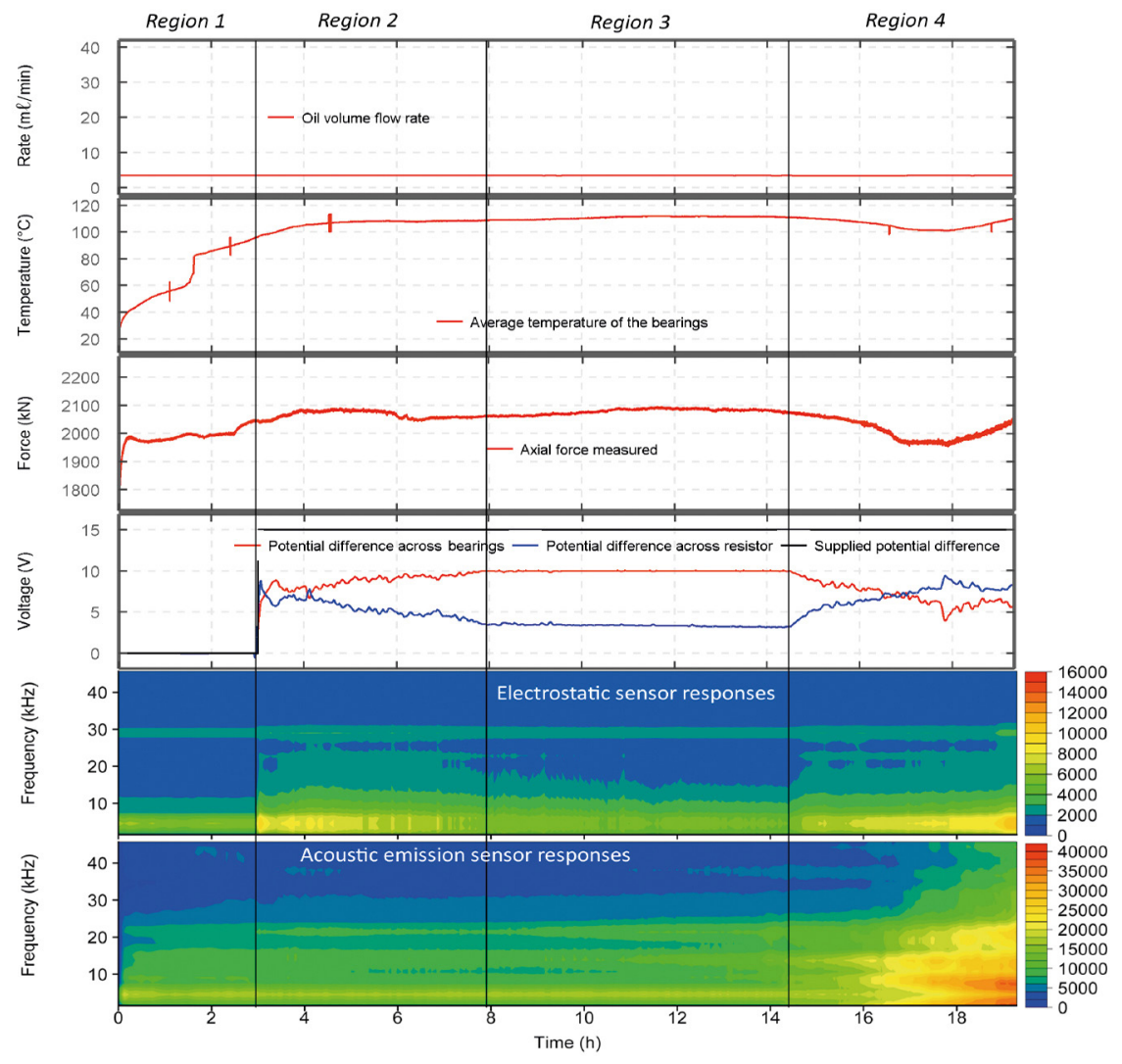

Figure 5. Test A: Rotational speed of $4500 \mathrm{r} / \mathrm{min}$, pre-load of $1800 \mathrm{~N}$, ambient pressure and lubricant temperature, lubricant flow rate of $3.4 \mathrm{~m} \ell / \mathrm{min}$ and applied electrical potential of $15 \mathrm{~V}$ at $3 \mathrm{~h}$, followed by the system shutdown at $19.3 \mathrm{~h}$ 
of the ES and AE signals, leading to region 4, the running-to-failure region. This region saw a gradual and continuous increase in the amplitude of the $\mathrm{ES}$ and $\mathrm{AE}$ signals until the system shut down due to the temperature of the bearings exceeding the $120^{\circ} \mathrm{C}$ limiting temperature. While the mechanisms for the increase in the $\mathrm{ES}$ and $\mathrm{AE}$ signals are not clear, it is thought that the ES sensor detected a combination of degradation mechanisms such as $\mathrm{CPD}$, triboemission and debris formation. For test A, where the electrical potential was present until the end of the test, the higher amplitude of the ES signals might have been due to the reoccurrence of high electrical discharges, posing additional charges.

In test $\mathrm{C}$, the second burst in the amplitude of the ES signals was not due to the electrical activities at the surface or the change in the electrical input, but was instead due to an increase in the lubricant flow rate that caused a high amplitude in the ES signals, possibly due to the double layer effect.

While all four regions were observed in both tests $A$ and $B$ and WECs were observed in the post-processing stage, region $4 \mathrm{did}$ not occur in test C. It is suggested that this is due to the increase in the lubricant flow rate from $3.4 \mathrm{ml} / \mathrm{min}$ to $40 \mathrm{ml} / \mathrm{min}$, altering the polarisation of the surfaces. In fact, WECs were only successfully created in this test-rig with a lubricant flow rate of below $8 \mathrm{ml} / \mathrm{min}$. Although the mechanism is still unknown, it is thought to be due to the activities at the surfaces that are favoured by the presence of electrical discharges and low lubricant flow rate.

\section{Conclusions}

For the first time, the feasibility of ES sensors in detecting WECs has been investigated. An ES wear site sensor has been installed on a bearing test-rig, while a number of bearing tests have been run to create WECs under electrical influences. Signals from the ES and the AE sensors have been collected at a very high sampling rate and analysed using the STFT method. The results from three bearing tests (two with WEC failures and one without) have shown that the ES sensor clearly responds to the electrical discharge events occurring at the bearing contacts.

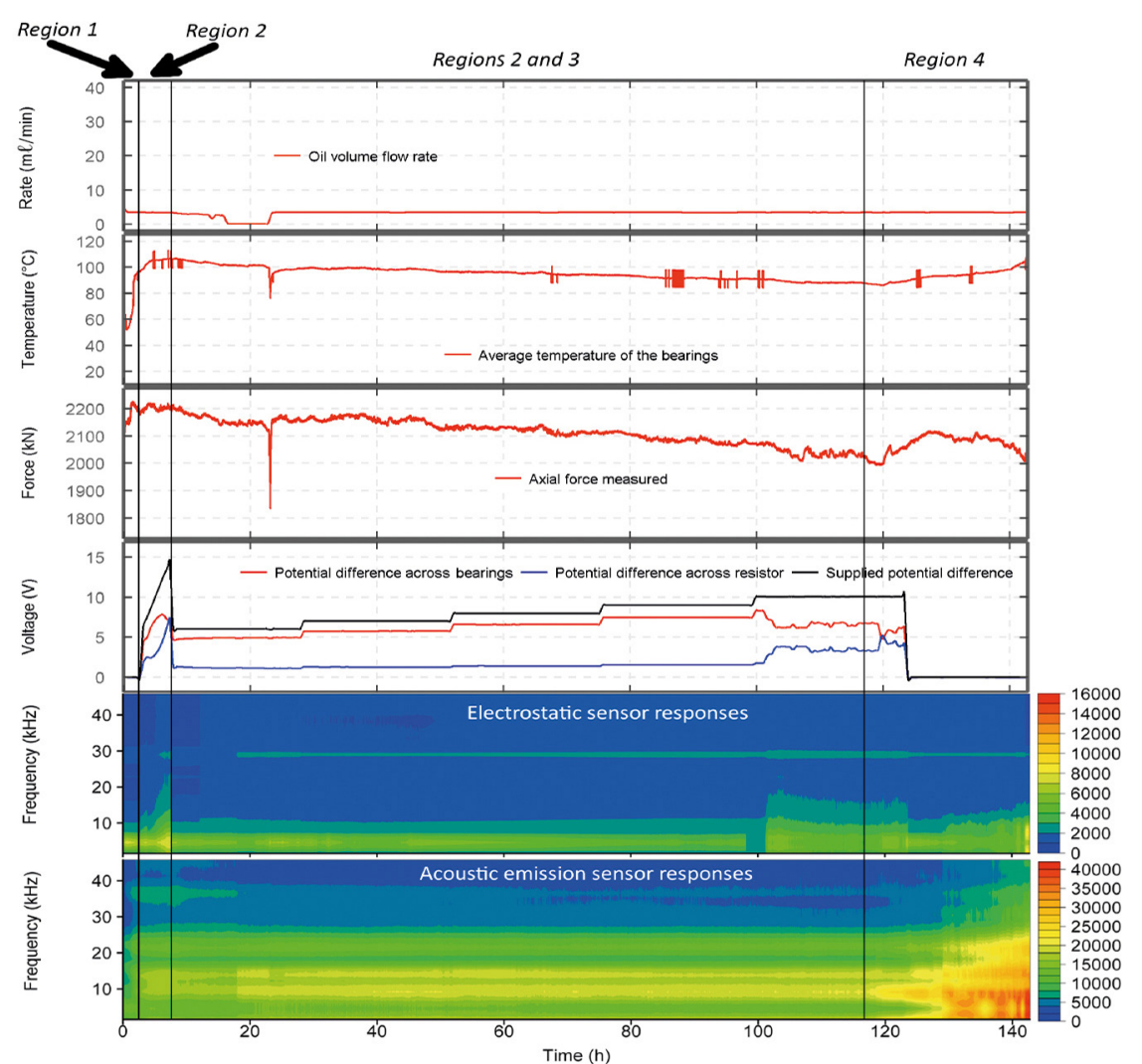

Figure 6. Test B: Rotational speed of $4500 \mathrm{r} / \mathrm{min}$, pre-load of $1800 \mathrm{~N}$, ambient pressure and lubricant temperature, lubricant flow rate below $5.5 \mathrm{m \ell} / \mathrm{min}$ and variable supplied electrical potential followed by the system shutdown at $142.6 \mathrm{~h}$

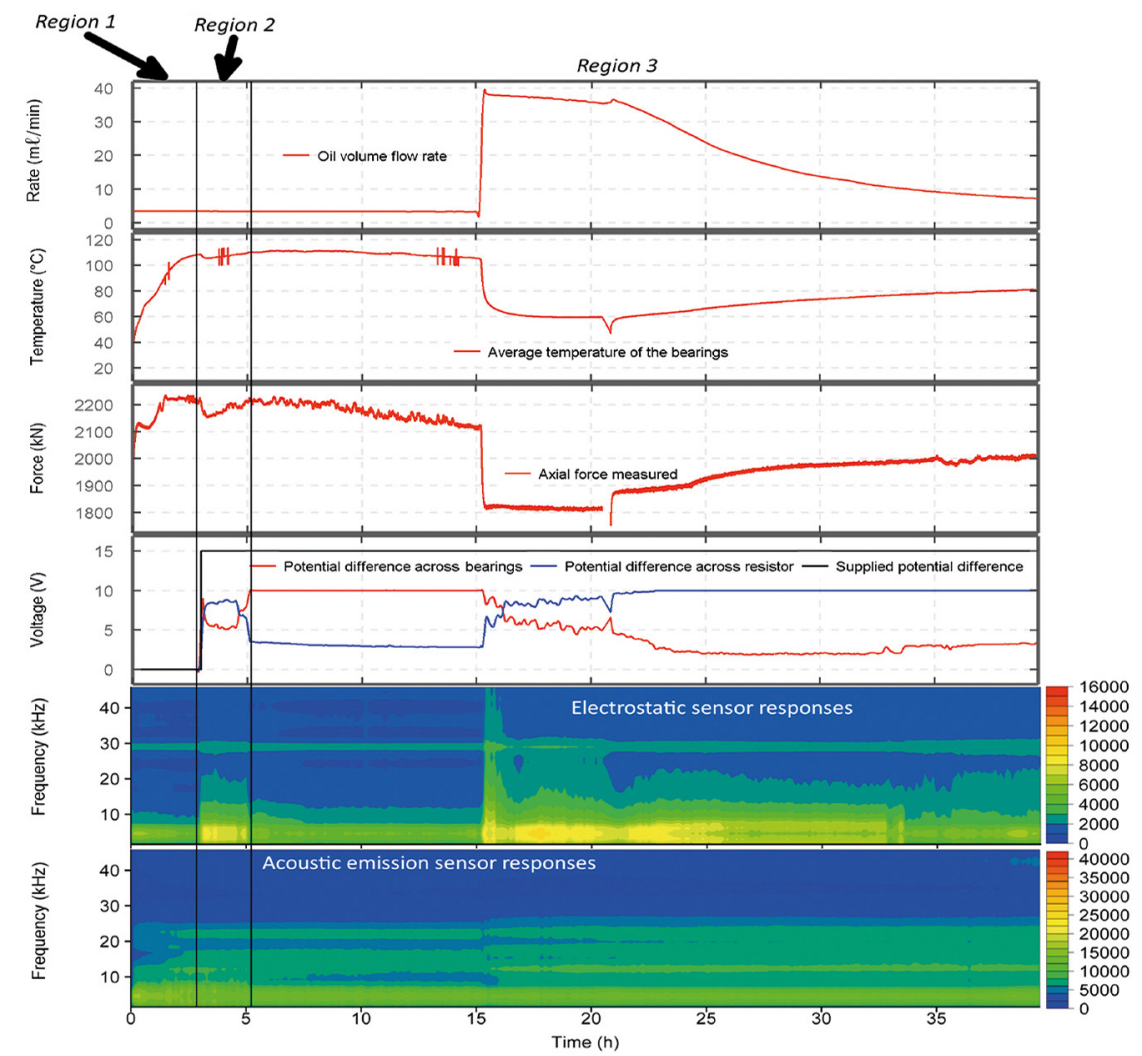

Figure 7. Test C: Rotational speed of $4500 \mathrm{r} / \mathrm{min}$, pre-load of $1800 \mathrm{~N}$, ambient pressure and lubricant temperature, variable lubricant flow rate and applied electrical potential of $15 \mathrm{~V}$ at $3 \mathrm{~h}$, followed by manual shutdown at $39.4 \mathrm{~h}$ 
This is thought to be due to the ES sensor measuring the electrical discharges resulting from an applied electrical potential greater than the lubricant field strength. The ES sensor has also detected changes in the lubricant flow rate, possibly due to the double layer effect. The main conclusions from this study are:

- Four distinctive regions have been identified in these WEC tests under electrical load influences, including a running-in period, charge/discharge region, steady state and running-tofailure region (leading to WEC failure);

- A sudden increase in the ES signals has been detected whenever electrical discharges are present. However, the electrical discharges started to diminish, possibly due to an increase in the electrical resistance of the contact; and

- A large change in the lubricant flow rate can also influence the charge measured in the ES signals, possibly due to the double layer effect.

A continuous increase in ES and AE signals is observed after the initial burst in the $\mathrm{ES}$ and $\mathrm{AE}$ signals marking the initiation of region 4, the running-to-failure region. Despite the $\mathrm{AE}$ sensor showing small increases due to degradation prior to the ES sensor, ES signals have been shown to respond to the electrical discharge and steady state period, which might be the precursor to region 4. The capability of the ES sensing technique in detecting these events prior to the degradation stage may have significant potential for diagnosing and prognosing a WEC failure event.

\section{Acknowledgements}

The authors would like to acknowledge Schaeffler Technologies AG \& Co KG, Germany, the Institute of Process Machinery and System Engineering in Erlangen, Germany, and QASS GmbH Qualität Automation Systeme Software, Germany, for their technical support.

This research has been funded by the University of Southampton and Schaeffler Technologies AG \& Co KG.

\section{References}

1. M-H Evans, 'An updated review: white etching cracks (WECs) and axial cracks in wind turbine gearbox bearings', Materials Science and Technology, Vol 32, No 11, pp 1133$1169,2016$.

2. J Loos, I Bergmann and M Goss, 'Influence of currents from electrostatic charges on WEC formation in rolling bearings', Tribology Transactions, pp 865-875, 2015.

3. M Zuercher, V Heinzler, E Schlücker, K Esmaeili, T J Harvey, W Holweger and L Wang, 'Early failure detection for bearings in electrical environments', The International Journal of Condition Monitoring, Vol 8, No 1, pp 24-29, February 2018.

4. S Barteldes and W Holweger, 'Using high-frequency impulse measurement (HFIM) for detection of lubrication-driven WEC formation', Proceedings of the 19th World Conference on Non-Destructive Testing (WCNDT), Munich, Germany, pp 13-17, 13-17 June 2016.
5. W Holweger, M Wolf, D Merk, T Blass, M Goss, J Loos, S Barteldes and A Jakovics, 'White etching crack root cause investigations', Tribology Transactions, Vol 58, No 1, pp 59-69, 2015.

6. J Luyckx, 'White etching crack failure mode in roller bearings: from observation via analysis to understanding and an industrial solution', Rolling Element Bearings, ASTM International, pp 1-25, 2012.

7. J Luyckx, 'Hammering wear impact fatigue hypothesis WEC/irWEA failure mode on roller bearings', NREL Workshop, pp 15-17, 2011.

8. M-H Evans, 'White structure flaking (WSF) in wind turbine gearbox bearings: effects of 'butterflies' and white etching cracks (WECs)', Materials Science and Technology, Vol 28, No 1, pp 3-22, 2012.

9. M-H Evans, A D Richardson, L Wang and RJ K Wood, 'Effect of hydrogen on butterfly and white etching crack (WEC) formation under rolling contact fatigue (RCF)', Wear, Vol 306, No 1, pp 226-241, 2013.

10. V Šmel̦ova, A Schwedt, L Wang, W Holweger and J Mayer, 'Microstructural changes in white etching cracks (WECs) and their relationship with those in dark etching regions (DERs) and white etching bands (WEBs) due to rolling contact fatigue (RCF)', International Journal of Fatigue, Vol 100, pp 148-158, 2017.

11. M Kohara, T Kawamura and M Egami, 'Study on mechanism of hydrogen generation from lubricants', Tribology Transactions, Vol 49, No 1, pp 53-60, 2006.

12. J Igba, K Alemzadeh, C Durugbo and E T Eiriksson, 'Analysing RMS and peak values of vibration signals for condition monitoring of wind turbine gearboxes', Renewable Energy, Vol 91, pp 90-106, 2016.

13. D Siegel, W Zhao, E Lapira, M AbuAli and J Lee, 'A comparative study on vibration-based condition monitoring algorithms for wind turbine drivetrains', Wind Energy, Vol 17, No 5, pp 695-714, 2014.

14. $\mathrm{T}$ Yoshioka and $\mathrm{T}$ Fujiwara, 'Paper II(i): Measurement of propagation initiation and propagation time of rolling contact fatigue cracks by observation of acoustic emission and vibration', Tribology Series, Vol 12, pp 29-33, 1987.

15. T Yoshioka, 'Detection of rolling contact subsurface fatigue cracks using acoustic emission technique', Lubrication Engineering, Vol 49, No 4, pp 303-308.

16. J Loos, M Goß and I Bergmann, 'Einfluss von Strömen aus elektrostatischen Aufladungen auf die WEC-Bildung in Wälzlagern', Gesellschaft für Tribologie Tagungsband, No 7, pp 1-14, 2014.

17. H E G Powrie, R J K Wood, T J Harvey and S Morris, 'Re-analysis of electrostatic wear-site sensor data from FZG gear scuffing tests', Wear, pp 6-12, 2001.

18. T J Harvey, R J K Wood, G Denuault and H E G Powrie, 'Investigation of electrostatic charging mechanisms in oil lubricated tribo-contacts', Tribology International, Vol 35, No 9, pp 605-614, 2002.

19. J E Booth, K D Nelson, T J Harvey, R J K Wood, L Wang, H E G Powrie and J G Martinez, 'The feasibility of using 
electrostatic monitoring to identify diesel lubricant additives and soot contamination interactions by factorial analysis', Tribology International, Vol 39, No 12, pp 1564-1575, 2006.

20. J E Booth, T J Harvey, RJ K Wood and H E Powrie, 'Scuffing detection of TU3 cam-follower contacts by electrostatic charge condition monitoring, Tribology International, Vol 43, No 1-2, pp 113-128, 2010.

21. K Nakayama, N Suzuki and H Hashimoto, 'Triboemission of charged particles and photons from solid surfaces during frictional damage', Journal of Physics D: Applied Physics, Vol 25, No 2, pp 303-308, 1992.

22. K Nakayama and H Hashimoto, 'Triboemission of charged particles and photons from wearing ceramic surfaces in various gases', Tribology Transactions, Vol 35, No 4, pp 643650, 1992.

23. K Nakayama, 'The plasma generated and photons emitted in an oil-lubricated sliding contact', Journal of Physics D: Applied Physics, Vol 40, No 4, pp 1103-1107, February 2007.

24. T J Harvey, R J K Wood, H E G Powrie and C Warrens, 'Charging ability of pure hydrocarbons and lubricating oils', Tribology Transactions, Vol 47, No 2, pp 263-271, 2004.
25. T J Harvey, S Morris, L Wang, RJ K Wood and H E G Powrie, 'Real-time monitoring of wear debris using electrostatic sensing techniques', Proceedings of the Institution of Mechanical Engineers, Part J: Journal of Engineering Tribology, Vol 221, No 1, pp 27-40, 2007.

26. T J Harvey, R J K Wood, G Denuault and H E G Powrie, 'Effect of oil quality on electrostatic charge generation and transport', Journal of Electrostatics, Vol 55, No 1, pp 1-23, 2002.

27. S L Chen, M Craig, R J K Wood, L Wang, R Callan and $\mathrm{H}$ E G Powrie, 'Bearing condition monitoring using multiple sensors and integrated data fusion techniques', Proceedings of the Ninth International Conference in Vibrations in Rotating Machinery, pp 586-600, 8-10 September 2008.

28. T J Harvey, R J K Wood and H E G Powrie, 'Electrostatic wear monitoring of rolling element bearings', Wear, Vol 263, No 7-12, pp 1492-1501, 2007.

29. M Craig, T J Harvey, R J K Wood, K Masuda, M Kawabata and $\mathrm{H}$ E G Powrie, 'Advanced condition monitoring of tapered roller bearings, Part 1', Tribology International, Vol 42, No 11-12, pp 1846-1856, 2009.

30. J B Allen and L R Rabiner, 'A unified approach to short-time Fourier analysis and synthesis', Proceedings of the IEEE, Vol 65, No 11, pp 1558-1564, 1977.

\section{The Fifteenth International Conference on Condition Monitoring and Machinery Failure Prevention Technologies CM2018 / MFPT2018}

II From sensors, through diagnostics and prognostics, to maintenance

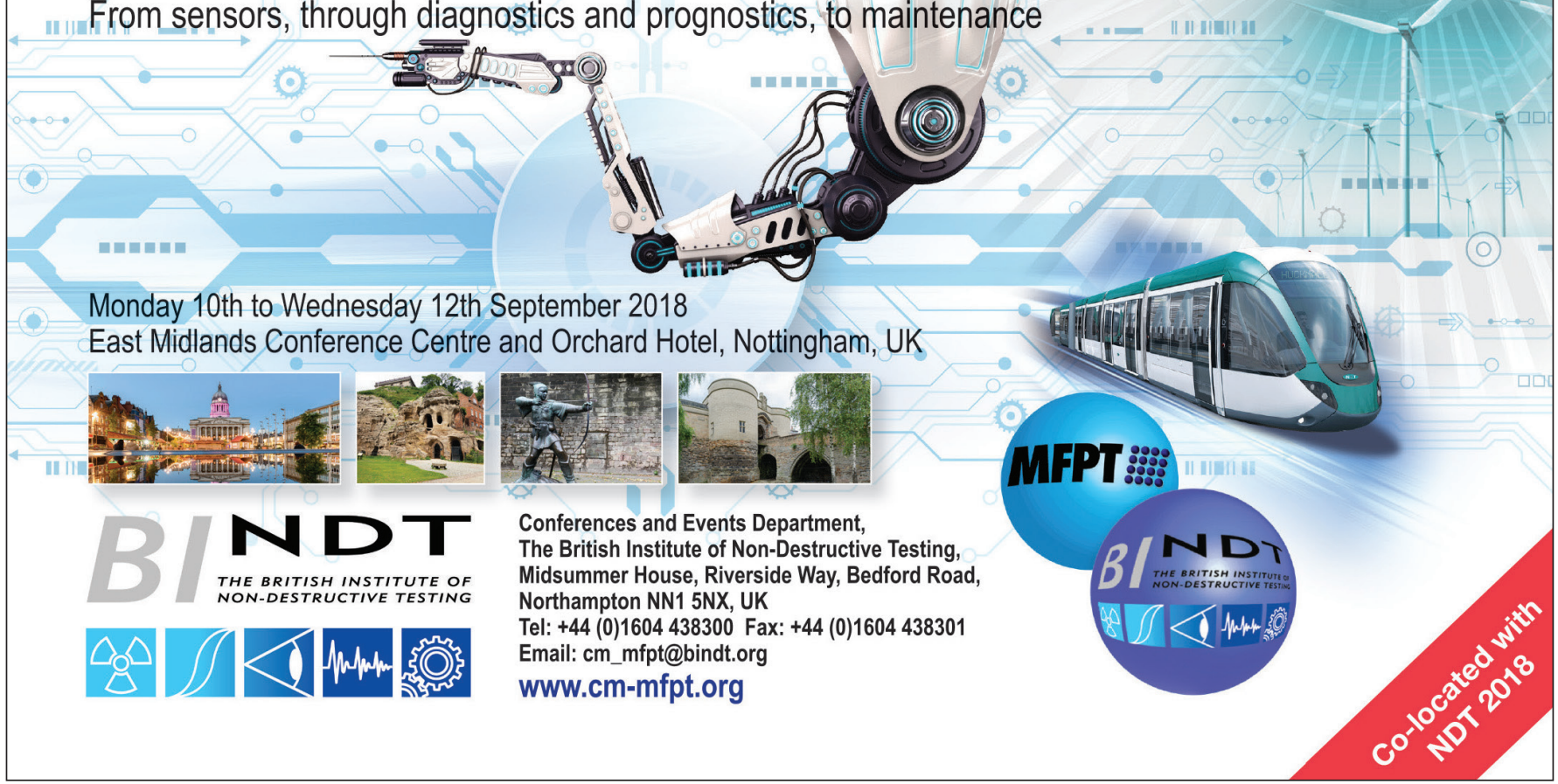

